\title{
AN APPARENT CEAP INCONSISTENCY: SHOULD THE CLASSIFICATION BE REVISED?
}

\author{
Fausto Passariello1, Malay Patel ${ }^{2}$, Pier L. Antignani ${ }^{3}$ \\ 'Vascular Surgeon, Centro Diagnostico Aquarius, Napoli, Italy \\ ${ }^{2}$ Vascular Surgeon \& Endovascular Specialist, Ahmedabad, India \\ ${ }^{3}$ Angiologist. Director Vascular Center, Nuova Villa Claudia, Rome, Italy
}

\section{REVIEW PAPER}

Phlebological Review 2015; 23, 1: 4-8

DOI: $10.5114 /$ pr.2015.51625

Submitted: 21.01.2015

Accepted: 06.04.2015

\section{ADDRESS FOR CORRESPONDENCE}

Dr Fausto Passariello

Vascular Surgeon, Centro Diagnostico

Aquarius,

Via Francesco Cilea, 280

80127 Napoli, Italy

e-mail: afunzionale@tiscalinet.it

\section{THE VASCULAB DISCUSSION ABOUT CEAP}

This paper took form following a discussion on the Vasculab message list that showed that phlebologists are not entirely satisfied with the current CEAP classification, many of them pointing out several obscure and ambiguous points which, in theory, could be improved.

We believe that 20 years after the original publication of the CEAP classification and 10 years after its revision, the time in now mature to ask whether further revision is necessary.

\section{THE ORIGINAL CEAP CLASSIFICATION}

CEAP is a score designed to give a synthetic description of chronic venous insufficiency (CVI). CEAP is an acronym from C - Clinical, E - Etiological, A - Anatomical, P - Pathological.

The original CEAP classification (Maui, Hawaii, 1994) is reported in two papers from 1996, by Beebe [1] and Kistner [2]. There are also some previous papers, but the Maui Consensus summarizes all the essential information.

\section{THE FIRST CEAP REVISION}

A CEAP revision published in 2004 [3] by the "ad hoc" Committee of the American Venous Forum essentially adds the $\mathrm{C}_{0}$ class and divides $\mathrm{C}_{4}$ into the $\mathrm{C}_{4 \mathrm{a}}$ and $\mathrm{C}_{4 \mathrm{~b}}$ subclasses. The $\mathrm{n}$ subscript is added to the other letters to include the conditions of 'no choice' or 'not applicable'.

Moreover, in order to simplify the evaluation, a BASIC version is provided for the 'A' letter, (divided into the subclasses s - Superficial, d - Deep and p - Perforators ) and for the ' $\mathrm{P}$ ' letter (divided into the subclasses $\mathrm{r}$ - Reflux, $\mathrm{o}-$ Obstruction and ro - Reflux and Obstruction). The 'Pn' coding means 'no detected pathology'.

The ADVANCED version, which was previously proposed for the 'A' letter in 1994 and shifted instead into the ' $\mathrm{P}$ ' letter in 2004, consists of additional codes from 1 to 18: superficial veins from 1 to 5 , deep veins from 6 to 16 , perforators from 17 to 18 (Table 1 ).

\section{THE ' $C$ ' COMPONENT OF THE CEAP CLASSIFICATION AND THE LYMPHEDEMA ISSUE}

To avoid improper evaluation, the ' $\mathrm{C}$ ' class should only be stated after completion of all the necessary clin- 
ical and instrumental investigations, in order to rule out the case or instead to classify it with CEAP. For instance, if a non-venous cardiac oedema is diagnosed, the patient is ruled out and CEAP cannot be used.

In addition, a healthy individual should not be coded as $\mathrm{C}_{0}$ or be described by CEAP as $\mathrm{C}_{0} \mathrm{E}_{\mathrm{n}} \mathrm{A}_{\mathrm{n}} \mathrm{P}_{\mathrm{n}}$, since some items in the letters ' $\mathrm{E}$ ', 'A' or 'P' must be positive to use the term $\mathrm{C}_{0}$. In simple words, the $\mathrm{C}_{0}$ code should be used for a phlebological patient who is clinically negative but has some abnormalities present in etiology and venous anatomy or pathophysiology.

Pure lymphedema is not considered in the CEAP classification (not classified as $\mathrm{C}_{3}$ ). At the moment it remains unclear whether lymphatic oedema coexisting with venous oedema, the so-called phlebolymphedema, should be considered together with venous oedema in the $\mathrm{C}_{3}$ class or should be coded separately using a new "L" descriptor: as $\mathrm{C}_{3 \mathrm{~L}}$, or should not be described at all using the CEAP classification.

\section{THE 'E' COMPONENT OF THE CEAP CLASSIFICATION - COEXISTING ETIOLOGIES}

Current CEAP classification considers the $\mathrm{C}$ (congenital), P (primary) and S (secondary) subclasses of the 'E' category as mutually exclusive items (likewise radio buttons), while in real life they are often seen simultaneously in the same patient. Patients with a congenital or primary venous disorder could later undergo a complication by a superimposed thrombosis which is a secondary pathology.

Thus, congenital features could be accompanied by secondary lesions, as in a Klippel-Trenaunay syndrome with a superimposed thrombosis of the marginal vein. It is difficult to describe such a patient using current CEAP classification.

In this case, the use of more than one item in a non-mutually-exclusive way $\left(\mathrm{E}_{c, s}\right)$ could provide an acceptable solution.

\section{THE A-P INCONSISTENCY - CONFLICTING CEAP VERSIONS}

There is an apparent inconsistency between the two CEAP releases.

In detail: the original CEAP classification places the anatomical segment designations into the anatomical ' $A$ ' category, while the CEAP revision includes them in the pathological 'P' category.

More exactly into the two Reflux (r) and Obstruction (o) subgroups. No relevance is given to the use of capitals or small caps in the terms.

The 'A' - 'P' position shift is repeated many times, in a congruent way. However, all the most recent papers [4] do not report the shift, conforming, instead, to the descriptions of the previous 'A' category, as if the inconsistency were simply a misconception. It remains unclear if this was a mistake, or if, instead, this change in classification was intended by the Authors.
Were it only an erroneous position shift in the revision paper [3], due to a superficial editing of the text before publication, other Authors neglecting the error could be acceptable and correct.

However, this interpretation does not hold because the shift is present in several points of the revised CEAP paper, in a coherent and congruent manner. On the other hand, no one pointed out the eventual coding error, which should have been read in a completely different way.

Nevertheless, the reported shift could also present some points of interest and seems somewhat advantageous as demonstrated in the following observations

\section{A-P INCONSISTENCY EXAMPLES}

Two similar clinical cases are presented (Fig. 1, cases $\mathrm{A}$ and $\mathrm{B})$.

In case A the GSV is refluxing above-the-knee (AK) and completely occluded below-the-knee (BK). The AK

Table 1. The advanced terms of the anatomic segment designation ( $\mathrm{A}$ in the original, $\mathrm{P}$ in the revision)

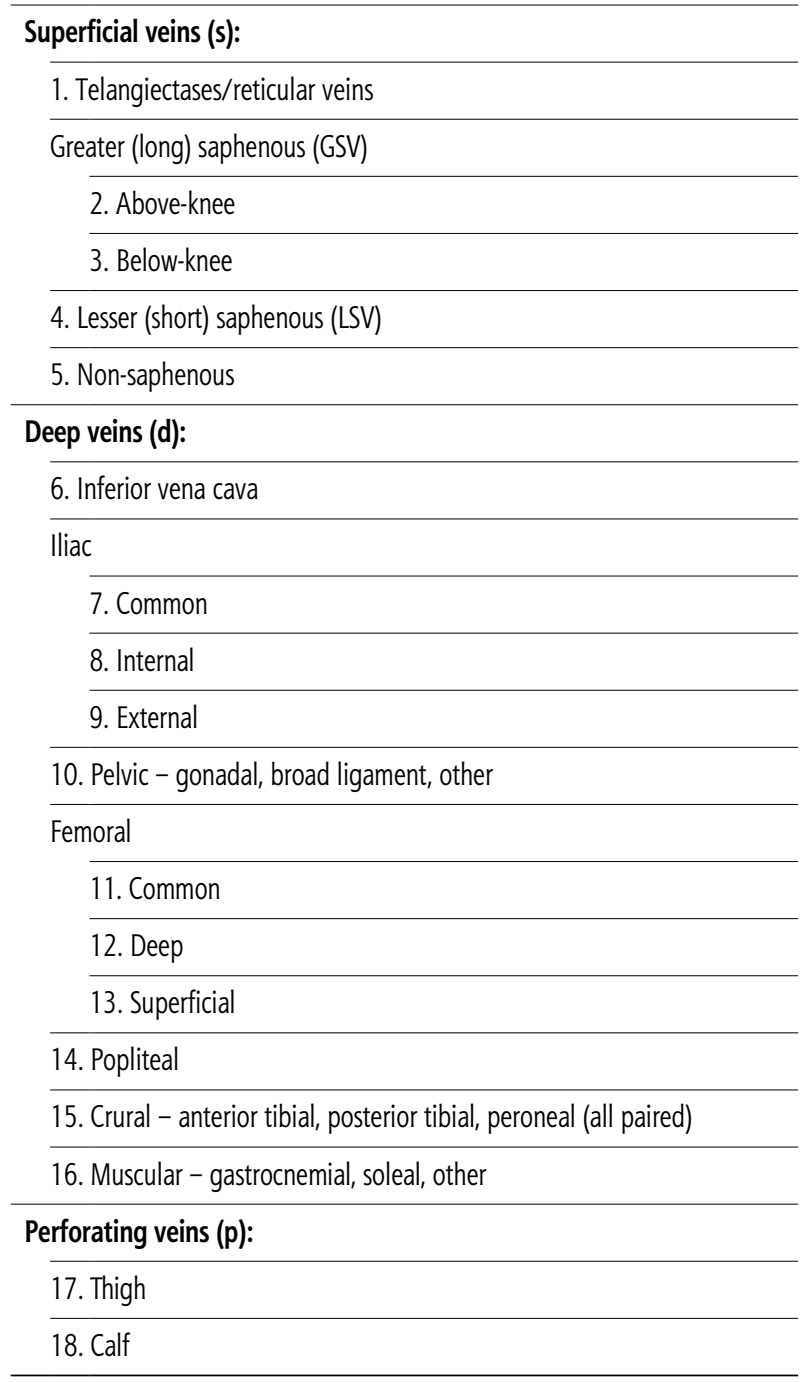




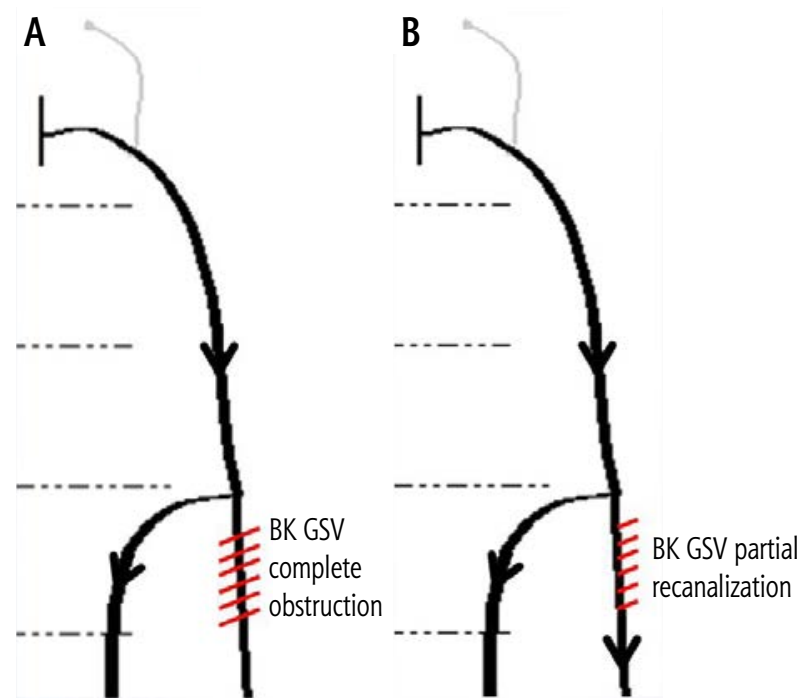

Fig. 1. Two schematic clinical cases. A) AK GSV reflux and BK GSV complete occlusion. B) GSV total reflux and BK GSV partial recanalization. In both cases a non-saphenous refluxing tributary coexists. See text for explanations

AK - above the knee; BK - below the knee; GSV - greater saphenous vein

reflux is then accepted downwards by a non-saphenous tributary, whose incompetence is required for the existence of the reflux.

In case B the GSV is similarly refluxing in the AK segment, but the $\mathrm{BK}$ segment is re-canalized.

The reflux is then accepted downwards both by the BK GSV and by the non-saphenous incompetent tributary, which is no longer needed to allow the GSV reflux.

Table 2 shows synthetically the details of the CEAP classification for both cases, using the original and revised versions. The 55 code accounts for the non-saphenous incompetent tributary.

In both cases, the original CEAP captures, under the letter 'A', the involvement of the AK and BK GSV as $A_{s 2,3,5}$ ', irrespective of the type of pathology (Reflux or Occlusion), while the pathologic conditions are described under the letter ' $\mathrm{P}$ ' as $\mathrm{P}_{\mathrm{r}, \mathrm{o}}$, without specifying where the pathology lies.

Thus, the original CEAP would code both patients exactly the same.

In both cases, the revised CEAP captures, under the letter 'A', the involvement of the superficial venous sys-

Table 2. Changes in the advanced terms in the clinical cases $A$ and $B$ in Fig. 1, according to the original CEAP and to the revision respectively. The original is unable to differentiate the cases, while the difference is clearly delineated by the revision. The $\mathrm{s}_{5}$ code in the examples accounts for the non-saphenous incompetent tributary

\begin{tabular}{|c|c|c|}
\hline CEAP version & original & revised \\
\hline case A & \multirow{2}{*}{$A_{s 2,3,5} P_{r, 0}$} & $A_{s} P_{r s 2,5,0 s 3}$ \\
\hline case B & & $A_{s} P_{r s 2,3,5,053}$ \\
\hline
\end{tabular}

tem as As. However, for case A the AK reflux and the BK occlusion are registered as $\mathrm{P}_{\mathrm{r} 22,5,0 \mathrm{os} 3}$, while for case $\mathrm{B}$, presenting with refluxing and partially occluded BK GSV, this is coded as $\mathrm{P}_{\mathrm{rr} 2,3,5,0,03^{3}}$.

Hence, the revised CEAP allows differentiation between the cases and is also able to give an efficient description of a refluxing partial recanalization, where partial thrombosis is implicit in the representation (coexisting Reflux and Obstruction), though not explicitly declared. Thus, the revised CEAP is more informative.

Some difficulties arise in the A-P uncertainty with telangiectasia, coded s1. It is easily included in the 'A' category $\left(\mathrm{A}_{\mathrm{s} 1}\right)$, while it cannot be represented at all in the $\mathrm{R}$ or $\mathrm{O}$ subgroups under the letter ' $\mathrm{P}$ '. It is unclear if this is of any importance; after all, in clinical practice nobody describes a refluxing or occluded telangiectasia.

\section{REFLUX AND THROMBOSIS}

CEAP deals with chronic venous disease, thus acute venous thrombosis, whether superficial or deep, cannot be coded with this classification.

Regarding chronic venous thrombosis, instead, several possible but non-mandatory improvements of the ( $\mathrm{r}, \mathrm{o})$ subgroups of the letter $\mathrm{P}$ could allow multiple choices (thus eliminating the need for the ro item).

In addition, the possibility of differentiation between chronic superficial versus deep thrombosis outcomes could be considered, as well as differentiation between complete versus partial thrombosis. Furthermore, it would be desirable to differentiate between a partial thrombosis which does not progress to occlusion and a partial recanalization after complete occlusion.

\section{CEAP AS A WHOLE}

It should be remembered that CEAP is not a clinical dossier but only the description or the instantaneous image of a patient at a given moment. The score is useful to communicate this image to operators at distance in space and time.

The CEAP classification presents some inter-observer variability. Its clinical reproducibility was investigated in a recent paper [5] with a moderate concordance in $60 \%$ of cases.

CEAP cannot be used to follow the evolution of CVI, which may be achieved, however, using other tools such as the Venous Clinical Severity Score (VCSS), the Recurrent Varicose Veins after Surgery score (REVAS) $[6,7]$ and the PREsence of VArices after operatIve Treatment (PREVAIT) [8].

\section{THE CEAP-SHUNTS COMPATIBILITY ISSUE}

The shunt classification is a theoretical framework regarded "by a few outstanding interventionists" [9] 
as an essential tool for the comprehension of chronic venous diseases, since it is strictly linked to the surgical choices in conservative surgery. The ' $A$ ' and ' $P$ ' approach of CEAP seems not to be in conflict with the shunt classification. They may simply be complementary points of view and a future CEAP revision could include, to some extent, information from the shunt classification.

\section{THE CHEAP EXTENSION}

In 2000 an anatomical and hemodynamic extension of CEAP was proposed with the name of CHEAP [10-12], in order to add detailed morphological and functional information to CEAP.

Without details regarding its implementation, the CHEAP extension may turn out to be of practical use, or may be interesting but not practical in its current form, or may prove to be a completely useless complication.

\section{THE CEAP SURVEY}

On the Vasculab message list [13] it was decided to make a survey to serve as a preliminary step for gathering essential information about difficulties and uncovered situations which could provide useful hints for a future revision.

It was not planned as an anonymous survey, personal data being gathered in order to weigh the answers according to expertise, to avoid duplicate answers and to contact contributors if and when new developments become available.

Questions regarding CEAP as a whole were placed at the end of the survey, thus allowing congruence between general and detailed answers provided for each item.

The main interest was to check the routine use of CEAP and its usefulness in daily clinical practice, which part is the most common, appropriate and easy use and how frequently it is used in its complete form.

In several countries (i.e. USA and Sweden) the 'C' classification is a criterion to select the reimbursement of therapeutic procedures. Is this is an acceptable use of CEAP?

A CEAP revision could be necessary, maybe simplification or maybe, in contraposition, greater precision is needed.

The CEAP survey is available online [14] and as a more friendly downloadable text version [15].

The current work is not intended to be limited to the Vasculab Community, and is, therefore, open to contributions from other interested groups.

\section{ACKNOWLEDGEMENTS}

We thank the Vasculab Community for having supported this work and especially the experts who partici- pated actively in the discussion (in alphabetical order): P.L. Antignani, L. Blomgren, R. Cuaranta, L. Grondin, C.R. Lattimer, S. McMaster, E. Mendoza, T. O’Donnell, F. Passariello, M. Patel, A. Pieri, P. Pittaluga, C. Recek, D. Wright, I. Zolotukhin.

The authors declare no conflict of interest.

\section{References}

1. Beebe H.G., Bergan J.J., Bergqvist D., Eklof B., Eriksson I., Goldman M.P., Greenfield L.J., Hobson II R.W., Juhan C., Kistner R.L., Labropoulos N., Malouf G.M., Menzoian J.O., Moneta G.L., Myers K.A., Neglen P., Nicolaides A.N.,O’Donnell T.F., PartschH., et al. Classification and grading of chronic venous disease in the lower limbs. A consensus statement. Eur J Vasc Endovasc Surg 1996; 12: 487-92.

2. Kistner R.L., Eklof B., Masuda E.M. Diagnosis of chronic venous disease of the lower extremities. The "CEAP" classification. Mayo Clin Proc 1996; 71: 338-345.

3. Eklof B., Rutherford R.B., Bergan J.B., Carpentier P.H,. Gloviczki P., Kistner R.L., Meissner M.H., Moneta G.L., Myers K., Padberg F.T., Perrin M., Ruckley C.V., Smith P.C., Wakefield T.W.; American Venous Forum International Ad Hoc Committee for Revision of the CEAP Classification. Revision of the CEAP classification for chronic venous disease: a consensus statement. J Vasc Surg 2004; 40: 1248-1252.

4. Padberg F.T. CEAP Classification for Chronic Venous Disease. Dis Mon 2005; 51: 176-182.

5. Sinabulya H., Holmberg A., Blomgren L. Interobserver variability in the assessment of the clinical severity of superficial venous insufficiency. Phlebology 2015; 30: 61-65.

6. Chiesa R., Marone E.M., Limoni C., Volontè M., Petrini O. Chronic venous disorders: Correlation between visible signs, symptoms, and presence of functional disease. J Vasc Surg 2007; 46: 322-330.

7. Maurins U., Hoffmann B.H., Loesch C., Joeckel K.H., Rabe E, Pannier F. Distribution and prevalence of reflux in the superficial and deep venous system in the general population - results from the Bonn Vein Study, Germany. J Vasc Surg 2008; 48: 680-687.

8. Perrin M. Presence of varices after operative treatment: a review. Phlebolymphology 2014; 21: 158-68.

9. Gloviczki P., Comerota A.J., Dalsing M.C., Eklof B.G., Gillespie D.L., Gloviczki M.L., Lohr J.M., McLafferty R.B., Meissner M.H., Murad M.H., Padberg F.T., Pappas P.J., Passman M.A., Raffetto J.D., Vasquez M.A., Wakefield T.W. (Society for Vascular Surgery. American Venous Forum). The care of patients with varicose veins and associated chronic venous diseases: clinical practice guidelines of the Society for Vascular Surgery and the American Venous Forum. J Vasc Surg 2011; 53 (5 Suppl): 2S-48S.

10. Passariello F. CHEAP: A standard file format for interchange of Hemodynamic and venous information on venous diseases. Lagos-Algarve, Portugal 2000. Available at the address http:// web.tiscali.it/afunc/chivaref/passarie/cheap.htm. Accessed on line on Jan 20th, 2015.

11. Passariello F. CHEAP: un formato file standard per lo scambio di informazioni emodinamiche e CEAP sulle malattie venose. Atti del XIII Congresso del Collegio Italiano di Flebologia. 
Udine, Italia 2003. Available at the address http://web.tiscali.it/ afunc/chivaref/passarie/mevch_ab.htm. Accessed on line on Jan 20th, 2015.

12. Passariello F. CHEAP: a haemodynamic file format. 21st World Congress of the International Union of Angiology, Rome, may 22-26, 2004. Available at the address http://web.tiscali.it/afunc/ chivaref/passarie/mevch_ab.htm Accessed on line on Jan 20th, 2015.

13. AA. Vasculab Yahoo Groups. The Vascular List. Message \#9232-9292. https://it.groups.yahoo.com/neo/groups/vasculab/ conversations/messages/9232 Accessed on line on Jan 20th, 2015. A free registration is required.

14. The on line CEAP Survey. http://www.vasculab.it/VLAB/ CEAP/CEAPSurvey.htm Accessed on line on Jan 20th, 2015.

15. The CEAP Survey text version. http://www.vasculab.it/VLAB/ CEAP/theCEAP_SurveyDocVersion.doc Accessed on line on Jan 20th, 2015. 